\title{
AS RESPOSTAS DE CARLOS FELIPE MOISÉS À INESGOTÁ VEL QUESTÃO: "PARA QUE SERVE A POESIA?"
}

Felippe Nildo Oliveira de Lima ${ }^{1}$

MOISÉS, Carlos Felipe. Poesia para quê? A função social da poesia e do poeta. São Paulo: Editora Unesp, 2019.

No mundo contemporâneo, perguntar para que serve a poesia, ou de que ela nos serve, em uma ordem discursiva que requer uma explicação restritiva amparada na utilidade econômica, não chega a uma resposta, mas a várias. E, quanto mais estas se aproximam de seu objeto de questionamento e reflexão, mais precisam recorrer à própria poesia para defender sua presença na vida cotidiana. Assim como a leitura de um poema provoca uma sensação de novidade a cada vez que é feita, o interrogar-se do porquê de a poesia persistir há milênios e ainda nos provocar afetações até hoje é um exercício que não se limita. E, pode ser também um exercício poético. É o que faz Carlos Felipe Moisés em Poesia para quê? A função social da poesia e do poeta, livro lançado em 2019 pela editora da Unesp, dois anos após a morte do professor, crítico literário e poeta.

A obra, dividida em 12 ensaios escritos em diferentes momentos da vida do autor, possui um eixo de sentido que ele recorrentemente elabora como "uma só pergunta básica, quanto ao papel social da poesia e do poeta” (MOISÉS, 2019, p. 9). No primeiro ensaio, “A poesia ensina a ver", o autor contextualiza o pensar da poesia em sociedade a partir do desacordo do trabalho poético com as engrenagens dominantes. Entretanto, a poesia sobrevive porque encontra "ouvidos humanos" que a propagam e a multiplicam no cotidiano. Essa necessidade de comunicação e escuta, que caracteriza a sobrevivência da poesia desde os primórdios, é entendida por Moisés a partir da disponibilidade do ouvinte/leitor em negar "o conhecimento enquanto resultado, a fim de privilegiar o próprio ato de conhecer" (2019, p. 24).

Retornando à expulsão platônica do poeta da polis, "A poesia nos ensina a ver" defende que não só pelos ouvidos, mas também a partir do olhar, a poesia transmite um

\footnotetext{
${ }^{1}$ Mestrando do Programa de Pós-Graduação em Letras da UFPB, com área de concentração em Literatura, teoria e crítica. Com auxílio de bolsa Capes, vem desenvolvendo pesquisa de mestrado sobre as poéticas contemporâneas e seus desdobramentos políticos.
} 
conhecimento que nos ensina a ver de novo e melhor, a ponto de aquilo com o qual nos deparamos (a ideia ou a coisa) passar a existir "como se nunca o tivéssemos visto antes" (MOISÉS, 2019, p. 23, grifo do autor). Essa postura poética de renovar nosso olhar marca o caráter insubmisso da poesia em meio a tudo o que está sedimentado pela rotina mecanizada. Logo, uma das lições da poesia, "no encalço da renovação e do aperfeiçoamento ilimitado", retoma seu "eterno confronto com o simulacro de 'perfeição' imposto pela ideia sectária e utilitarista de uma sociedade esvaziada de memória, consagrada ao consumo e à descartabilidade de todas as coisas." (MOISÉS, 2019, p. 24).

Em "Make it new", o autor visita a sabedoria milenar chinesa presente nos ideogramas do poeta Tching - traduzidos por Ezra Pound em Os Cantos (2015) como "make it new" ("faça-o novo, faça isto novo") -, ao discutir a tarefa da poesia de trazer o novo e tornar novas as coisas do mundo. Essa relação dos poetas - para Pound, as "antenas da raça" - com o tempo, no sentido de renová-lo, fez com que a poesia moderna se aproximasse, mediante a experimentação exacerbada de suas técnicas, meios, materiais, suportes e recursos, do desejo capitalista de "entronizar o avanço, a mudança incessante e a expansão sem limites" (MOISÉS, 2019, p. 69). Entretanto, diferenciando-se do tempo da técnica e da ciência, que é desenfreadamente ávido por uma novidade que torna obsoleto tudo o que lhe é precedente, para Carlos Felipe, a poesia não deve perder de vista o velho ou o passado na forma de uma tradição de vozes poéticas outras. Ao contrário, atua na transformação do velho em novo para construir um presente contínuo, no qual nova se faz justamente nossa reintegração ao mundo pela via da atemporalidade da poesia.

Em "Pelos olhos e pelos ouvidos" e "Da praça pública à mansarda", o autor se detém nas condições de produção e circulação da produção poética. O primeiro texto discorre sobre a habilidade de a poesia atingir o leitor na solitude de seus sentidos e afetos. Essa solidão, fruto da migração da poesia oral para o meio impresso, fez da leitura um "vício solitário" (MOISÉS, 2019, p. 75) ligado unicamente ao indivíduo, não mais a uma coletividade ouvinte. É interessante como o autor compara os diferentes efeitos políticos gerados pela vivência poética através dos meios oral e escrito. Segundo exemplo dado na obra, enquanto letras de música foram bastante censuradas no período do regime militar brasileiro, os livros de poesia não sofreram tanta perseguição na mesma época. Nesse sentido, perguntar-se sobre a funcionalidade social da poesia em meio impresso é buscar em seu contato solitário os elementos oriundos da subjetividade 
do poeta que, mediante a experiência do leitor, "podem migrar para a realidade e transformar-se em outra coisa." (MOISÉS, 2019, p. 77, grifo do autor).

Em "Da praça pública à mansarda", aprofundando a questão da solitude inerente à experiência com a poesia moderna, Moisés observa como os poetas precisaram se isolar para não se perder em meio ao ritmo da vida coletiva. O crítico amplia sua percepção sobre a condição à deriva da poesia moderna à própria busca de o "homem comum que, sentindo-se 'excluído', pode vir a se identificar com o poeta, [...], no encalço de um ‘rosto próprio’ e de autoafirmação.” (MOISÉS, 2019, p. 108). A partir do compartilhamento das solidões do poeta e do leitor em um mundo que os aliena de si mesmos, "A poesia nos ajuda a conviver com nossa interioridade, não como forma de isolamento nem como repúdio à realidade de fora, mas como experiência decisiva, que conduz à sintonia com o mundo em redor.” (MOISÉS, 2019, p. 121).

Para Carlos Felipe Moisés, entretanto, o apelo à poesia por parte não só do poeta como também de seus leitores para situar-se em um lugar próprio (e poético) no mundo, que atribua sentidos às suas existências individuais, não recebe uma solução. A poesia, assim, não teria o poder de dar uma resposta à pergunta universal "Quem sou?", fundamento da relação humana com as manifestações artísticas. Neste sentido, continua o autor, “A poesia não é a saída, apenas aponta caminhos. [...] A poesia será, quando muito, um exemplo de atitude, a ser recriada pelo leitor" (MOISÉS, 2019, p. 120, grifo do autor). Esta "atitude" seria multiplicada e ressoaria na política da vida coletiva por meio de indivíduos imersos em uma comunidade de partilha não só do gosto pelo trabalho dos poetas, mas também da multiplicidade dos direcionamentos e caminhos de autoconhecimento abertos através da leitura. Essa tarefa da poesia, para Moisés (2019, p. 121), objetivaria, então, "reconstituir o ser coletivo, o tecido social que se esgarçou e nos reduziu a átomos; só assim voltaremos a nos irmanar no propósito comum de preservar a dignidade da condição humana.” (MOISÉS, 2019, p. 121).

Diferenciando-se dos ensaios discutidos acima, que estão fortemente ligados ao conteúdo e ao meio de veiculação da poesia, os textos "Palavra x imagem", "Verso livre ou O anfíbio alado", "Poema em prosa" e "Poesia e ortografia" discutem a função social da poesia e dos poetas a partir de questões suscitadas pela própria forma poética ou materialidade textual. Discordando da comparação antiga, de Horácio, da poesia e do poeta com a pintura e o pintor, Carlos Felipe Moisés privilegia a capacidade de a poesia operar com a imaginação, mesclando realidade e fantasia, convidando-nos ao desafio da liberdade (MOISÉS, 2019, p. 135). Logo, pode-se considerar como não só solitário, mas 
principalmente solidário o trabalho da poesia, por fazer com que as palavras atribuam novos sentidos ao real e construam utopias. Na forma de prosa poética, livre, rigorosamente metrificada e/ou somada a outras linguagens artísticas, a poesia utiliza igualmente o ritmo como uma forma de relação sensorial e afetiva com o indivíduo que o encaminha à busca dos sentidos da liberdade: "Poesia continua a ser o reino da liberdade, e liberdade quer dizer solidariedade, via de mão dupla.” (MOISÉS, 2019, p. $135)$.

Buscar o sentimento da liberdade na palavra poética é transcender as possíveis amarras da forma, o que só é possível graças ao verdadeiro e engenhoso ofício que os poetas empreendem com a linguagem, que, no ensaio "O mito da inspiração", é questionado pelo autor se seria resultante da inspiração ou do trabalho de concentração do poeta. Os paradoxos que residem em uma concepção de poesia como dom inato possuído por poucos privilegiados ou como fruto da árdua lida do poeta profissional levantam questões importantes às formas como os poetas se veem e são vistos socialmente. Essa discussão complementa-se às ideias do ensaio "A questão do valor", no qual Moisés reflete acerca do valor da poesia para a crítica, sua questionadora institucionalmente mais qualificada, e para a formação do gosto estético popular.

Esses ensaios mais voltados às formas poéticas e ao trabalho propriamente dito dos poetas no manejo dos artifícios da linguagem possibilitam à obra uma visada mais ampla por sobre os aspectos sociais da poesia, indo do conteúdo à forma e da subjetividade do eu empírico do poeta às suas ressonâncias na realidade. Essas movimentações, longe de criarem oposições entre poesia e vida social, mostram, no decorrer de toda a obra, como ambas se complementam de forma indissociável:

Poesia: enredamento circular. É matéria de vida e isso pode não ser nada; é mera virtualidade, mas tem a ver com nossa vida e busca naturalmente a forma da expressão verbal, para nos dizer que ainda é, mas já não é mais, e logo depois se desdobra em mais matéria de vida ou de poesia, e assim indefinidamente. (MOISÉS, 2019, p. 191-192).

Por fim, os dois últimos ensaios da obra, "A hora da poesia" e "A verdadeira vida", voltam-se à seguinte questão: para que nos serve a poesia na sociedade brasileira em que vivemos? Os textos deixam antever que ela se propõe também a ser um projeto político em meio a uma vida cada vez mais efêmera e imediatista, com direitos e democracia combalidos. Ler poesia, nesse sentido, é também ver a vida como ela é, só que de outra forma, para que possamos fazer a defesa (poética) da vida como ela 
poderia ser. Poesia. Devir. Suscitadora de várias respostas que se contradizem e/ou complementam entre si, a leitura de Poesia para quê?, guiada por seu título-pergunta, faz com que o próprio leitor precise revisitar sua experiência de leitura de poesia e de convivência com seus livros e poetas preferidos para refletir o quanto a poesia está presente em sua vida, em sua relação com o mundo e as pessoas. Volta-se, portanto, à questão levantada desde o início da obra, quando Carlos Felipe Moisés (2019, p. 11) considera que

ao mesmo tempo que é ponto de chegada, síntese do que vinha tentando formular desde muito antes, este Poesia para quê? contém ainda um bom feixe de dúvidas e perplexidades, a pedir desdobramentos cujo termo eu não seria capaz de divisar.

A leitura de Poesia para quê? propicia ao leitor desenvolver os desdobramentos citados pelo autor em torno do pensamento da função social da poesia e do ofício do poeta. Como pontos de partida, os questionamentos levantados por Carlos Felipe Moisés induzem o leitor a elaborar seus próprios caminhos para pensar a poesia neste tempo em que vivemos. Esse interrogar constante tem sido, inclusive, bastante presente em nossa produção contemporânea, na busca de validar o falar poético em meio às adversidades do real que cala e mata as possibilidades de poesia. É o que podemos encontrar no poema "Para que poetas em tempos de terrorismos?", de Alberto Pucheu (2017, p. 25):

[...] para que poetas em tempos de terrorismos?
para que poetas em tempos de terrorismo
religioso de todos os lados do planeta? para que
poetas em tempos de terrorismo da verdade
plena e integralmente revelada? para que poetas
em tempos de terrorismo midiático? para que
poetas em tempos de terrorismo econômico? [...]

Para quem, como eu, compartilha os efeitos dos terrorismos enunciados no poema acima, a poesia constitui um modo de ser outro diante do mundo. Para além do que está dito, na materialidade do papel ou nas vozes dos poetas, quando a poesia se torna vida, questionar sua serventia deixa de ser urgente. Entretanto, a vivência íntima e contínua com a poesia e os poetas não deixa de constantemente nos oferecer elucidações possíveis para justificar a importância de seu lugar em nossas vidas. A cada vez que nos identificamos com um poema e conseguimos experimentar a vida de forma um pouco melhor ou mais lúcida, em meio aos terrorismos de um cotidiano nada poético, podemos 
não só encontrar possíveis respostas do para quê da poesia mas, principalmente, sentilas dentro de nós mesmos.

\section{Referências}

MOISÉS, Carlos Felipe. Poesia para quê? A função social da poesia e do poeta. São Paulo: Editora Unesp, 2019.

POUND, Ezra. Os cantos. Rio de Janeiro: Nova Fronteira, 2015.

PUCHEU, Alberto. Para que poetas em tempos de terrorismos? Rio de Janeiro: Azougue, 2017. 